\title{
Regionalização da Pegada Hídrica do Estado da Paraíba
}

\section{Regionalization of the Water Footprint of the State of Paraíba}

\section{Regionalización de la Huella Hídrica del Estado de Paraíba}

\author{
Kettrin Farias Bem Maracajá, Dr ${ }^{\mathbf{a}}$ \\ Professora Adjunta da Universidade Federal do \\ Rio Grande do Norte \\ Av. Sílvio Bezerra de Melo, 755, \\ Sitio, CEP: 59.380-000 - Currais Novos, RN - Brasil \\ Telefone: (84) 3405-2836, e-mail: kettrin@gmail.com
}

\author{
Lincoln Eloi de Araújo, Dr. \\ Professor Adjunto - Universidade Federal da \\ Paraíba, Centro de Ciências Aplicadas e Educação - \\ Campus IV - DEMA.
}

Rua da Mangueira, S/N, CEP: 58.297-000 - Rio

Tinto, PB - Brasil, Telefone: (83) 3291-1528, e-mail: lincolneloi@yahoo.com.br

Vicente de Paulo Rodrigues da Silva, Dr. Professor da Universidade Federal de Campina Grande, CTRN Endereço: Rua, Aprígio Veloso, 882, Bairro Universitário, CEP: 58.429-140, Campina Grande, PB, Brasil. Fone: (83) 2101-1000 e-mail: vicente@dca.ufcg.edu.br

\section{RESUMO}

$\mathrm{O}$ conceito de pegada de água $(\mathrm{PH})$ tem sido utilizado como um indicador do volume total anual de água doce que é usado para produzir os bens e serviços consumidos pelos habitantes da nação. O objetivo deste artigo consiste em elaborar a regionalização PH no Estado da Paraíba; e, assim, quantificar o uso consuntivo de água de sua população nas diferentes mesorregiões do estado. Os resultados indicaram que PH média do Estado da Paraíba é de 796 $\mathrm{m}^{3}$ /ano per capita enquanto as mesorregiões da Mata paraibana e Cariri paraibano apresentaram maiores e as menores pegadas hídricas, respectivamente. A PH da população aumenta linearmente com a sua renda familiar, com coeficiente de determinação de 0,89 no caso do grupo com a menor renda familiar. A pegada hídrica da população aumenta em função da renda familiar e diminui de acordo com os hábitos alimentares.

Palavras-chave: Água virtual. Dieta alimentar. Recursos hídricos.

\section{ABSTRACT}

The water footprint concept (PH) has been used as an indicator of the total annual volume of freshwater that is used to produce the goods and services consumed by the inhabitants of the nation. The aim of this paper is to develop a regionalization of PH in Paraiba sate for quantify the consumptive water use for its population in different mesoregions state. The results indicated an average PH in Paraíba state is 796 $\mathrm{m}^{3} /$ year per capita while the mesoregions of Mata paraibana and Cariri paraibano had the highest and lowest PH values, respectively. The PH of the population increases linearly with their family income,

\footnotetext{
${ }^{1}$ Artigo recebido em 22.11.2013. Revisado pelos pares em 11.03.2014 (blind review). Ajustado e Aceito para publicação em 15.03.2014. Recomendado para publicação por José Ribamar Marques de Carvalho (Editor Científico). Publicado em 10.04.2014. Organização responsável UACC/CCJS/UFCG.
}

REUNIR: Revista de Administração, Contabilidade e Sustentabilidade ISSN: 2237-3667 ISSN: 2237-3667 - Vol.4, no 1, p. 105-122, 2014. 
with a coefficient of determination of 0.89 in for the group with the lowest family income. The water footprint of the population increases as a function of family income and decreases according to the eating habits.

Keywords: Virtual water. Diet. Water resources.

\section{RESUMEN}

El concepto de huella hídrica (PH) se ha utilizado como indicador del volumen total de agua dulce que se utiliza para producir los bienes y servicios consumidos por los habitantes de la nación. El propósito de este artículo es desarrollar la regionalización PH en el estado de Paraíba, y así cuantificar el uso consuntivo del agua de su población en estado diferente meso. Los resultados indicaron que el promedio del estado de Paraíba PH es 796 m3/año per cápita, mientras que el meso Paraibana Forestal y Cariri mostraron huellas de agua más grandes y más pequeños, respectivamente. El PH de la población se incrementa linealmente con el ingreso familiar, con un coeficiente de correlación de 0,89 en el caso del grupo de ingresos más bajos. La huella hídrica de la población aumenta en función de la renta familiar y disminuye de acuerdo a los hábitos alimenticios.

Palabras clave: Agua virtual. La dieta. Los recursos hídricos.

\section{INTRODUÇÃO}

A humanidade nos últimos anos vivencia um período de grande crise em relação ao seu crescimento e degradação ambiental, sendo necessária uma reflexão sobre os problemas causados pela sociedade e a sua influência sob o meio ambiente. $\mathrm{O}$ equilíbrio ambiental entre o homem e a natureza torna necessária a criação de indicadores do uso da água baseados em metodologias que contemplem índices de sustentabilidade do uso direto e indireto de água (ERCIN et al., 2011). A sustentabilidade de uma pegada hídrica (PH) depende inteiramente de fatores locais, tal como as características hídricas da região. Por exemplo, uma $\mathrm{PH}$ grande se torna sustentável em áreas ricas em água, enquanto uma $\mathrm{PH}$ pequena pode comprometer a sustentabilidade em áreas com escassez de água. A PH é definida como o volume total de água utilizado durante a produção e consumo de bens e serviços, bem como o consumo direto e indireto no processo de produção. A determinação da PH é capaz de quantificar o consumo de água total ao longo da cadeia produtiva (YU et al., 2010). A maioria dos usos de água ocorre na produção agrícola, destacando-se também um número significativo do volume de água consumido e poluído nos diversos setores industriais e domésticos.

O aumento do uso da água doce está relacionado com o aumento da população do planeta que pode provocar problemas de escassez e de poluição, que acontece principalmente pelo uso de pesticidas na agricultura, esgotos sanitários e pelos poluentes lançados no ar e na água pelas indústrias. Nos dias atuais, tem sido bastante destacada a abordagem da limitação dos recursos hídricos (HOEKSTRA \& CHAPAGAIN, 2007, 2008). Portanto, é essencial o 
conhecimento das reais necessidades de consumo de água dos diversos de bens de consumo, como alimentos, bebidas, energia e das fibras naturais. Essa é uma informação relevante não apenas para os consumidores, mas também para os varejistas, comerciantes e empresas que desempenham papel central no fornecimento desses bens aos consumidores (ALDAYa et al., 2010). Dessa forma, surge a necessidade de um instrumento de medida dos fluxos de entrada e saída de recursos hídricos de um determinado local.

A retirada de água doce global aumentou quase sete vezes no século passado e esse valor deve crescer cada dia mais devido ao aumento populacional, bem como pelas diferentes mudanças de hábitos alimentares e de consumo (GLEICK, 2000). Desse modo, o volume de água de superfícies líquidas (rios lagos, etc) em determinado período não são totalmente disponíveis em face da evaporação, principalmente em regiões com alta demanda atmosférica, tal como em áreas áridas e semiáridas (SILVA et al., 2006). O aumento da demanda da água doce para o consumo humano e para a irrigação é outro problema que o mundo vem enfrentando atualmente (PERRY, 2007).

A água virtual tem sido uma solução parcial para os problemas da escassez de água, haja vista que regiões com baixa disponibilidade hídrica importam água contida nos produtos agrícolas consumidos pela população. Dessa forma, determinada região pode ser uma forte importadora de água virtual cujo impacto da pegada hídrica fica na região de origem do produto. Por exemplo, enquanto moradores do Iêmen têm uma pegada hídrica média de 619 $\mathrm{m}^{3}$ de água per capita por ano, os americanos consomem $2.482 \mathrm{~m}^{3}$ por pessoa no mesmo período (HOEKSTRA \& CHAPAGAIN, 2007). Os estudos sobre água virtual começaram a crescer devido aos estudos quantitativos publicados por vários pesquisadores (HOEKSTRA \& HUNG, 2005; HOEKSTRA, 2011).

Para Hoekstra \& Chapagain (2008) a definição mais precisa sobre água virtual consiste na mensuração da água contida num produto, ou seja, numa mercadoria, bem ou serviço, em relação ao volume de água doce utilizada nas diversas fases de sua cadeia produtiva. Nesse aspecto, o conceito de pegada hídrica tem sido usado como indicador do consumo de água de pessoas e produtos em diversas partes do mundo (VAN OEL et al., 2009; ZHAO et al., 2009; ROMAGUERA et al., 2010; FENG et al., 2011). Entretanto, no Brasil esse tema é ainda totalmente incipiente. Neste contexto, objetiva-se com este estudo determinar a pegada hídrica do Estado da Paraíba com vistas à quantificação do uso consuntivo de água da população nas diferentes mesorregiões do estado. 


\section{REFERENCIAL TEÓRICO}

O crescimento rápido da população mundial e o grande consumo de energia nas últimas décadas mudaram a forma do uso dos recursos naturais na terra (Hoekstra, 2008). Desse modo, surge o conceito da PH para determinar o tamanho da pegada humana que o planeta pode suportar. A PH de um indivíduo ou comunidade é definida pelo volume total de água doce que é usada para produzir bens e serviços consumidos pelo indivíduo ou comunidade (HOEKSTRA \& CHAPAGAIN, 2007b). O conceito de PH tem sido introduzida na comunidade científica a fim de demonstrar a importância da gestão da água.

A PH pode ser calculada para qualquer grupo de consumidores, bem como para uma atividade específica, bem ou serviço, sendo ela expressa em termos de volume de água doce por ano. Assim, a pegada de um indivíduo ou comunidade pode ser estimada pelo total de água utilizado na produção de bens e serviços relacionados a certo padrão de consumo tendo sido utilizado, dentro e/ou fora do território nacional (Hoekstra e Chapagain, 2008). No entanto, não são poucos os problemas ambientais causados pela má utilização da água doce, principalmente pelo fato das pessoas não saberem da quantidade utilizada na produção de alimentos e uso domésticos. Por outro lado, a água virtual pode ser definida como um indicador físico da quantidade de água necessária para produzir bens e serviços nas diversas fases da cadeia de produção sendo os produtos comercializados de um lugar para outro; enquanto que a $\mathrm{PH}$ indica a quantidade de água necessária para produzir bens e serviços que serão consumidos por um país ou indivíduo (RESENDE NETO, 2011).

Como se percebe, a compreensão dos fatores que interferem no cálculo da PH de uma população devem considerar os aspectos de ordem social, ambiental, política e econômica, assim como a área onde essas pessoas residem, visto que em algumas localidades a água é escassa e um bem precioso; devendo, portanto, ser melhor empregado. Por essa razão, a presente pesquisa foi realizada em todos os estados e regiões do Brasil para que se tenha com maior precisão o valor da $\mathrm{PH}$.

\subsection{Indicadores de sustentabilidade}

Segundo Bellen (2003), o termo indicador vem do Latim indicare significa revelar ou apontar para estimar ou mesmo colocar valor, podendo tornar perceptível uma tendência ou fenômeno que não são detectáveis imediatamente. Desse modo, os indicadores de sustentabilidade surgem como um método para operacionalizar o desenvolvimento sustentável, sendo feita uma análise da parte teórica que remetida para a prática se destaca por revelar 
informações sobre o estado das diversas dimensões que compõem o desenvolvimento sustentável da sociedade.

Os indicadores são medidas, atribuições de números a objetos, acontecimentos ou situações, de acordo com algumas regras. Enquanto medidas remetem às informações que são mensuráveis, independente de sua coleta, elas obedecem a técnicas ou abordagem qualitativas ou quantitativas. No entanto, os indicadores também devem ser analisados em termos operacionais, ou seja, de acordo com as categorias pelas quais estão inseridos e que possam ser medidos. Desse modo, entende-se como sendo indicador um parâmetro ou um conjunto de elementos que fornecem informações sobre um determinado fenômeno (GUIMARÃES et al., 2009).

Em relação ao critério de sustentabilidade, o sistema de indicadores apresenta metodologias diferenciadas relacionadas às dimensões ambiental, social e econômica. Para Bellen (2006), os indicadores devem ser utilizados para: comunicar informações sobre o progresso no alcance dos objetivos sociais; revelar fenômenos que não são imediatamente identificáveis; prover informações na forma quantitativa, as quais são mais eficazes do que palavras ou figuras isoladas; representar um modelo da realidade, mas não a realidade completa. Por outro lado, os indicadores possuem um papel fundamental para tomada de decisões e para formulação das políticas públicas. O referido autor observa os indicadores a partir das seguintes funções: a) avaliação de condições de tendências; b) comparação entre lugares e situações; c) avaliação de condições e tendências em relação às metas e aos objetivos; d) prover informações de advertência; e) antecipar futuras condições e tendências.

No Brasil, o IBGE disponibilizou para a sociedade a edição de indicadores de desenvolvimento sustentável, contendo 50 indicadores que tentam seguir as recomendações da Agenda 21, sendo 19 desses sociais, 18 ambientais, 9 econômicos e 4 institucionais. Logo, essas informações são remetidas a todos que têm envolvimento teórico e prático com os desafios do desenvolvimento, como os pesquisadores, formuladores de políticas, integrantes do setor público e privado das organizações sociais, assim como ao público em geral (IBGE, 2007).

\subsubsection{Pegada Ecológica}

Na década de 1990 surgiu o conceito de pegada ecológica como sendo a determinação da área de terra necessária para suprir as necessidades de uma dada população, sem que exista prejuízo ao ecossistema, levando em consideração a área necessária para se atender um sistema populacional urbano, a partir dos níveis de consumo, do desenvolvimento de novas tecnologias, da importação e exportação de produtos, da eliminação de espécies 
concorrentes, da eficiência da produção e da administração dos recursos naturais (MARACAJÁ \& CARVALHO, 2010). No entanto, vários estudiosos têm dúvidas sobre se esse conceito é útil na ciência e/ou na política. Ao mesmo tempo, o conceito de pegada ecológica atrai a atenção do universo acadêmico e inúmeras pesquisas começam a ser feitas. Deste modo, Hoekstra \& Chapagain (2008) descrevem que o conceito de PH adiciona uma nova perspectiva em relação à escassez de água, à dependência da água, ao uso sustentável da água e às implicações da gestão global do comércio virtual da água.

No ano de 1972, logo depois da Conferência das Nações Unidas (ONU), emergiu a preocupação com o desenvolvimento sustentável de modo que as pessoas possam aproveitar os recursos naturais hoje e no futuro próximo através do consumo.

Nesse contexto, foi proposto um modelo de desenvolvimento econômico que procurasse identificar os impactos ambientais visando à renovação natural dos ecossistemas. Logo, surgiram várias metodologias para se mensurar a sustentabilidade nos seus diferentes ambientes, sejam elas local, regional, nacional ou mundial, a partir de indicadores ambientais, dentre eles, a pegada ecológica (Ecological Footprint Method - EFM).

O conceito de pegada ecológica foi utilizado pela primeira vez no ano de 1992, no livro "Our Ecological Footprint - Reducing Human Impact on Earth", publicado em 1996 de acordo com William Rees, Professor na British Columbia University (Andrade, 2006). Nesse contexto, Dias (2002) definiu a pegada ecológica como sendo uma estimativa da quantidade de recursos necessária para produzir, de uma forma continuada, os bens e serviços que consumimos, e eliminar todos os resíduos poluentes que são produzidos, permitindo estimar áreas de terras ou água produtivas para sustentar a manutenção do sistema.

Desse modo, para se entender o que significa a pegada ecológica é necessário entender sua relação com a capacidade de carga, ou seja, a determinação da área de terra necessária para suprir as necessidades de uma dada população, sem que exista prejuízo ao ecossistema. O conceito leva em consideração a área necessária para se atender um sistema populacional urbano (a partir dos níveis de consumo, do desenvolvimento de novas tecnologias, da importação e exportação de produtos, da eliminação de espécies concorrentes, da eficiência da produção e da administração dos recursos naturais). Portanto, faz-se necessário mencionar que para se calcular a área apropriada por determinada população ocorre uma variação de acordo com o número de itens escolhidos, bem como a disponibilidade de dados sobre o consumo desses itens. Para Bellen (2006) existem quatro etapas para que seja feito o cálculo da pegada ecológica: 1) Calcular a média anual de itens de consumo de dados agregados, por exemplo, consumo de energia e de alimentos, dividindo o consumo total pelo tamanho da população; 2) Determinar ou estimar a área apropriada per 
capita para cada um dos principais itens de consumo, dividindo o consumo anual per capita pela produtividade média anual; 3) Calcular a área da pegada ecológica média por pessoa, somando as áreas do ecossistema apropriadas por cada item de consumo de bens ou serviços; e, 4) Calcular a área total apropriada multiplicando o resultado da etapa anterior pelo tamanho da população.

De acordo com Pereira (2008), o cálculo da pegada ecológica é dividido em duas partes: a oferta ecológica, ou seja, a biocapacidade, e o consumo da população que é a pegada. Por outro lado, quando ocorre a comparação se obtém um diagnóstico, que é: se a biocapacidade for maior do que a pegada, têm-se uma situação de saldo ecológico positivo; se a biocapacidade for menor do que a pegada, têm-se um déficit ecológico. Segundo Wackernagel \& Rees (1996), existem cinco categorias para agrupar os itens de consumo, sendo estes: a) alimentação: vegetais e carnes (de boi, aves, peixes); b) habitação: área construída (casa, apartamentos); c) transporte: público ou privado; d) bens de consumo: papel, máquinas, roupas, dentre outros; e) serviços: bancos, hospedagens, restaurantes, aeroportos, dentre outros.

Para um melhor entendimento, faz-se necessário entender o conceito de terras biologicamente produtivas, que segundo Andrade (2006) é definida como: "a terra que é suficientemente fértil para a plantação de florestas e agricultura". O espaço ecológico é representado pelas terras bioprodutivas que estão subdivididas em áreas de pastagem, de floresta e de cultivo, área de mar; terra de energia, terra pavimentada ou degradada e área para a proteção da biodiversidade. Ainda segundo a autora, as áreas de terras bioprodutivas podem ser definidas da seguinte forma: a) terras de pastagens - são as áreas de terras destinadas à criação de rebanhos de corte e de leite; b) terras de florestas são as áreas cobertas pelas florestas naturais ou plantadas para a produção de fibras, madeira e combustíveis; c) terras de cultivo - são as terras destinadas para o cultivo de alimentos e ração animal; d) área de mar bioprodutiva - são as áreas destinadas à pesca; e) território de energia - são as áreas fictícias em que se calcula o Ecological Footprint Method do $\mathrm{CO} 2$, estimando-se a área biologicamente produtiva necessária para seqüestrar as emissões de carbono suficientes para evitar um aumento desse gás na atmosfera; f) território construído - espaço pavimentado, construído ou degradado - formados pelas áreas destinadas à moradia, ao transporte, aos produtos industriais e às hidroelétricas; g) área de disponibilidade limitada - espaço destinado à proteção da biodiversidade - são compostos por áreas reservadas, formadas por matas virgens que têm como função proteger a biodiversidade, visando à reprodução das espécies oriundas da fauna e da flora e seqüestrar o gás carbônico produzido por intermédio das atividades.

Deste modo, o conceito de pegada ecológica é caracterizado por ser uma medida referente à apropriação humana de áreas produtivas enquanto que a 
pegada hídrica mede a apropriação dos seres humanos mediante o consumo de água doce do planeta. Ambas as pegadas têm em comum a análise do consumo humano mediante a utilização dos recursos naturais. Para um melhor entendimento sobre a medição das duas pegadas, a pegada ecológica utiliza o espaço (hectares) e a pegada hídrica o uso total de recursos de água doce (m3/ano). Estes dois indicadores devem ser vistos como sendo complementares em se referindo à utilização do capital natural em relação ao consumo humano dos recursos naturais (SEIXAS, 2011).

\subsubsection{Pegada Hídrica}

O conceito de PH foi introduzido em 2002 por Arjen Hoekstra na reunião de peritos internacional sobre o comércio da água virtual, realizada em Delf, Holanda. A PH das nações foram quantitativamente avaliadas por Hoekstra \& Hung (2002) e, posteriormente, de forma mais abrangente, por Hoekstra \& Chapagain $(2007 \mathrm{a}, \mathrm{b})$. O termo $\mathrm{PH}$ foi escolhido por Hoekstra, em analogia à pegada ecológica; no entanto, os conceitos referentes as pegadas possuem outras raízes, vista que pegada ecológica é expressa em hectares e a $\mathrm{PH}$ em volume de água doce consumida.

A PH foi introduzinda em busca de ilustrar as relações pouco conhecidas entre o consumo humano e o uso da água, bem como entre o comércio global e a gestão de recursos hídricos. Para Hoekstra (2003), o ponto de partida para essa pesquisa se deu com o descontentamento com o fato de que a gestão de recursos hídricos é geralmente vista como uma questão local ou no máximo como um problema que ocorre no âmbito de uma bacia hidrográfica.

As comunidades científicas e políticas têm supervisionado a dimensão global da gestão dos recursos hídricos em todo o mundo, de modo que se tenha uma idéia sobre o consumo de água pelos seres humanos (Hoekstra, 2006). A perspectiva (oferta) na gestão dos recursos hídricos é tamanha que dificilmente é reconhecido que o uso da água diz respeito ao consumo humano. O conceito de $\mathrm{PH}$ só foi discutido em fóruns de água e de ciência política; ainda não ocorreu um debate sobre essa temática em fóruns ambientais (Hoekstra et al., 2007a). Em 2002, na reunião de especialistas em Delf, o conceito passou a ser discutido em várias reuniões internacionais da água, como o 3o Fórum Mundial da Água no Japão em 2003, a Conferência sobre o Comércio Virtual e Geopolítica da Água, organizado pelo Conselho Mundial da Água em 2003 (WWC, 2004), a reunião de peritos sobre o Comércio Virtual da Água organizado pelo Instituto Alemão de Desenvolvimento, em Bonn no ano de 2005 (Horlemann \& Neubert, 2007), o IV Fórum Mundial da Água na Cidade do México em 2006, a reunião de peritos sobre Governança Global da Água organizada pelo Projeto de Sistema Global de Água, em Bonn, no ano de 2006 e 
na reunião de peritos sobre o Comércio Virtual de Água organizado pelo Instituto de Pesquisa Social-Ecológico em Frankfurt, em 2006 (Hummel et al., 2007). Esses foram os primeiros eventos que obtiveram destaque por estarem sendo pioneiros no debate sobre a temática da $\mathrm{PH}$ no mundo. A partir do ano de 2006 até os dias atuais foram mais de 50 eventos realizados em todo o mundo sobre esse assunto, destacando um dele que ocorreu no Brasil no ano de 2011, na cidade de São Paulo com um curso introdutório sobre essa temática. O evento foi realizado em duas etapas, na primeira apenas para os parceiros do grupo Water Footprint tendo como título: Regional WFN Partner Exchange Meeting realizado no dia 17 de março de 2011. A segunda etapa foi um treinamento sobre $\mathrm{PH}$ destinada às pessoas interessadas no tema: Regional Water Footprint training course in Brazil, realizado entre os dias 15-17 de março de 2011.

\section{MATERIAL E MÉTODOS}

\section{1 Área de estudo}

O Estado da Paraíba é uma das 27 unidades federativas do Brasil, estando situado na região Nordeste e tendo como limites os estados do Rio Grande do Norte ao Norte, o Oceano Atlântico a leste, Pernambuco ao sul e Ceará a oeste, e ocupa uma área de $56.439 \mathrm{~km}^{2}$ e a sua capital é a cidade de João Pessoa. O relevo se destaca pelo fato de possuir $66 \%$ do território entre 300 e 900 metros de altitude. O clima é tropical úmido no litoral, com chuvas abundantes; no entanto, no interior do estado, depois da Serra da Borborema, o clima se torna semiárido e sujeito às estiagens prolongadas, assim como precipitações abaixo de $500 \mathrm{~mm}$ (Silva, 2004). As temperaturas médias anuais ultrapassam os $28{ }^{\circ} \mathrm{C}$, com algumas exceções no Planalto da Borborema, onde a temperatura média do ar é em torno de $26^{\circ} \mathrm{C}$.

No tocante aos aspectos econômico, social e político, o Estado da Paraíba está dividida em 4 mesorregiões, de acordo com a classificação estabelecida pelo IBGE (Figura 1). As características de cada uma dessas mesorregiões são apresentadas a seguir: (i) Mata Paraibana (MP) - Possui o clima úmido que predomina todo litoral do estado. Essa mesorregião se destaca por ser a parte mais povoada e urbanizada do estado; (ii) Agreste Paraibano (AP) - É uma região de transição entre a zona da mata e a região do sertão. 


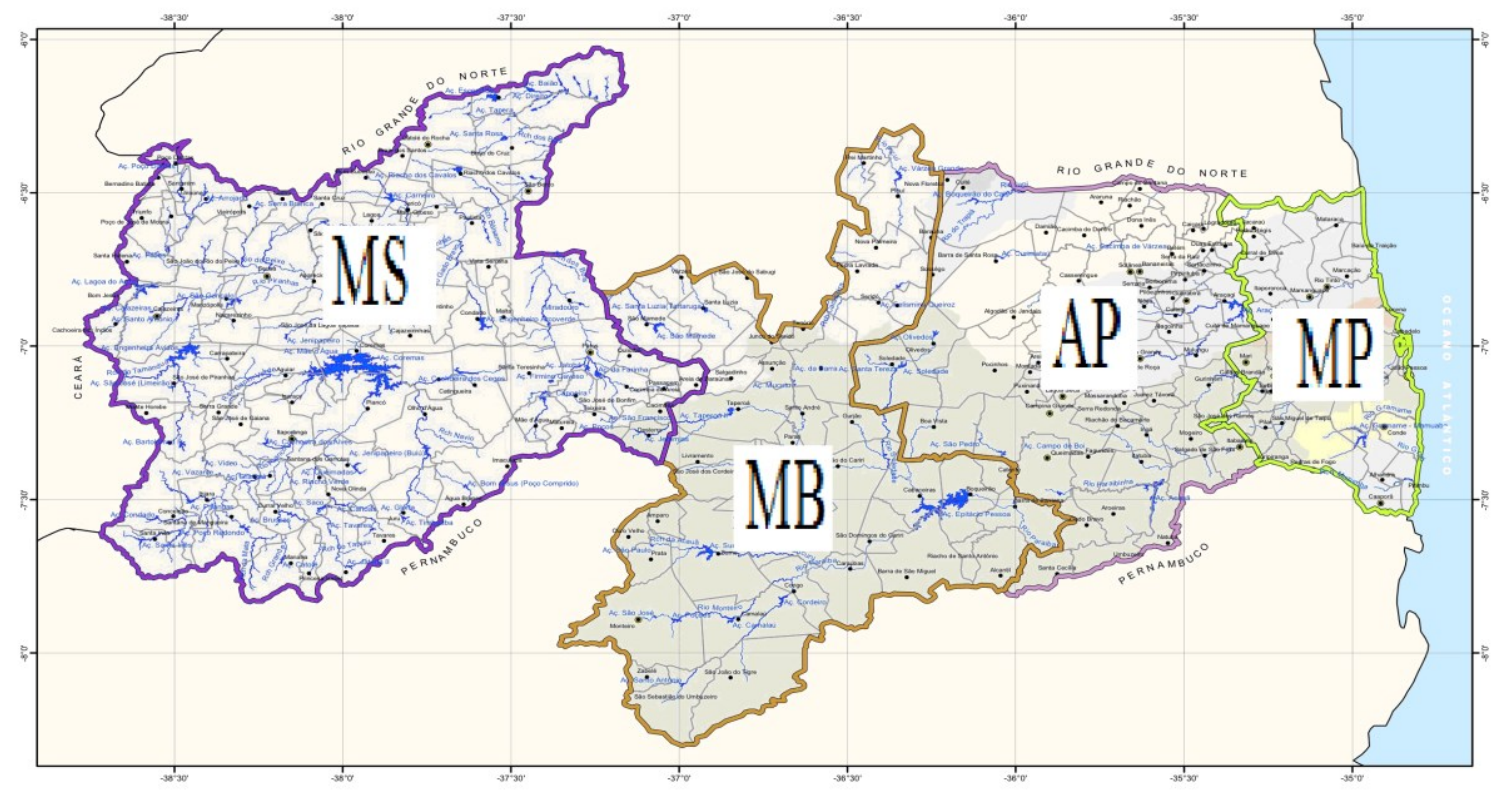

Figura 1. Mapa das mesorregiões do Estado da Paraíba (Aesa, 2009). Mata Paraibana (MP), Agreste Paraibano (AP), Mesorregião da Borborema (MB) e Mesorregião do Sertão (MS)

Fonte: Maracajá (2013)

Essa mesorregião possui clima semiárido, muito embora chova mais do que na Borborema e no sertão do estado. Ela se destaca por ter sua economia voltada para a cana-de-açúcar, algodão, sisal e a pecuária; (iii) Mesorregião da Borborema (MB) - Essa mesorregião se situa no planalto da Borborema, entre o sertão e o agreste paraibano, sendo a região com mais escassez de chuva. Na economia ressalta-se a extração mineral, sisal, algodão e a pecuária de caprinos; e (iv) Mesorregião do Sertão (MS) - Essa mesorregião faz parte da área do estado com clima mais seco do que a mesorregião da Borborema, com rios temporários e vegetação predominante sendo a caatinga. O principal produto cultivado na região é o algodão e a pecuária também é extensiva em toda área. Essas mesorregiões estão, por sua vez, desagregadas em 23 microrregiões geográficas. Tal divisão levou em consideração as características e as formas de organização socioeconômica e política.

\subsection{Coleta de dados da pesquisa}

Neste estudo foram selecionadas todas as messorregiões do Estado da Paraíba. As informações para a determinação da $\mathrm{PH}$ foram obtidas para cada município na base de dados do Instituto Brasileiro de Geografia e Estatística (IBGE). Inicialmente, foi realizada uma pesquisa de campo com a aplicação de questionários na cidade de Campina Grande, para aferir os hábitos alimentares da população com relação ao consumo de carne (alto, médio ou moderado) ou vegetariano. Posteriormente, foram extraídos dados do IBGE referentes à renda 
per capita, população, gênero masculino e feminino dos municípios baseados na última pesquisa realizada no ano de 2010. Essas informações foram extraídas de cada município utilizando-se a técnica do quartil para selecionar um conjunto de 83 municípios com renda per capita dentro do primeiro, segundo e terceiro quartis.

Os dados assim obtidos, juntos com os de hábitos alimentares, serviram de base para determinar a pegada hídrica da população paraibana. Os dados de renda anual foram convertidos para dólares americanos, utilizando-se a cotação do dia 11 de dezembro de 2012. Os municípios foram selecionados seguindo o critério de se obter um uma distribuição homogênea com vistas à espacialização das informações na área de estudo.

Nesta pesquisa, a pegada hídrica da população da área de estudo foi analisada em função de três vetores (variáveis), que são divididos em diferentes classes definidas da seguinte forma:

(i) Variável 1 (Sexo)

a) Classe I (masculino)

b) Classe II (feminino)

(ii) Variável 2 (Indicadores sociais municipais)

a) Rendimento mensal domiciliar per capita nominal (Valor médio - Total) - Nível 1 - primeiro quartil

- Nível 2 - segundo quartil

- Nível 3 - terceiro quartil

(iii) Variável 3 (Dieta alimentar)

a) Vegetariano

b) Alto consumidor de carne vermelha (consome carne todos os dias)

c) Médio consumidor de carne vermelha (consome carne três vezes por semana).

Os municípios foram selecionados seguindo o critério de ser obter um uma distribuição homogênea com vistas à especialização das informações coletadas com base em entrevistas e nos dados do IBGE (2010). Na Figura 2 é exibida a distribuição espacial dos municípios que foram analisados nesta pesquisa. 


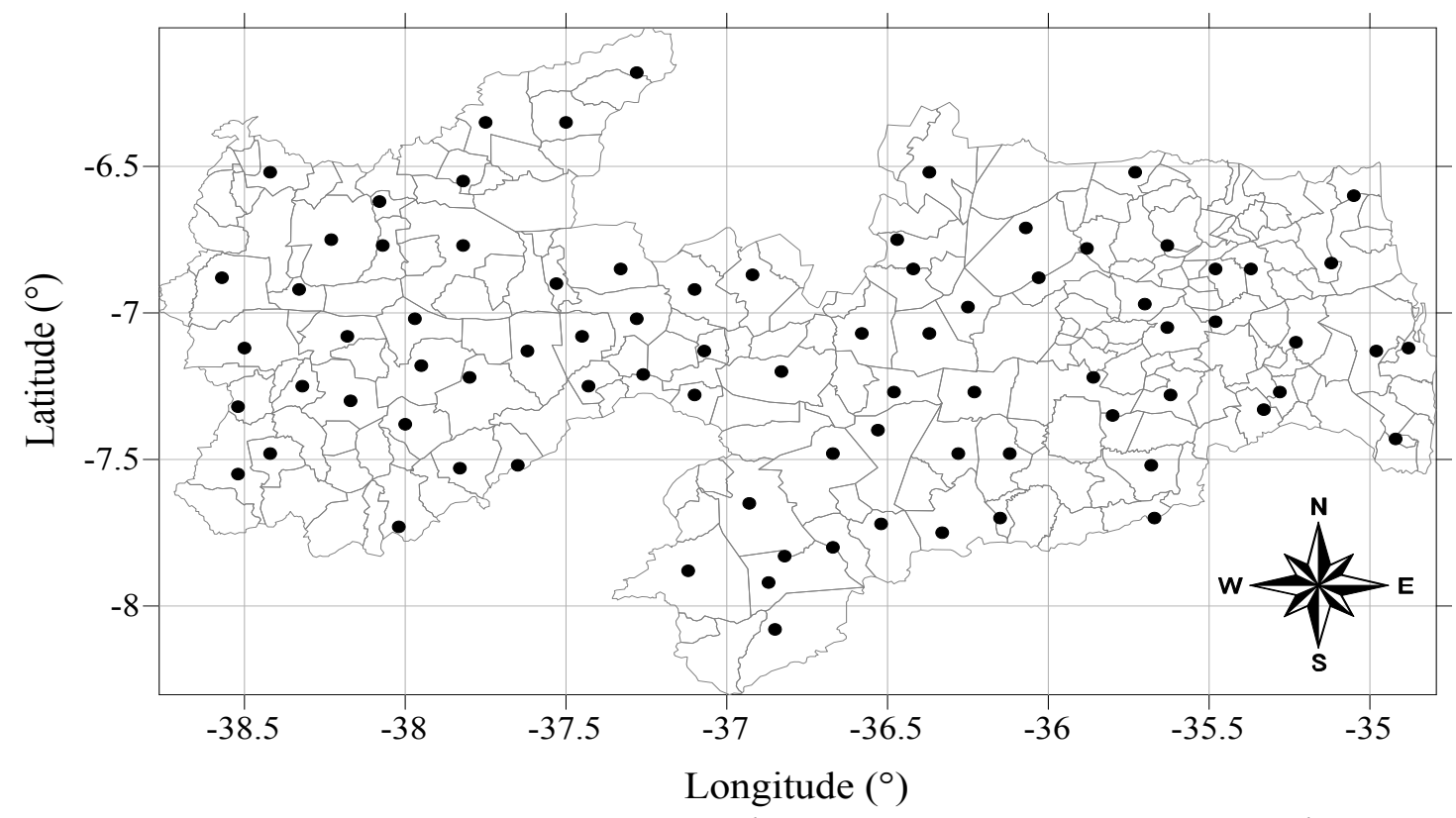

Figura 2. Distribuição espacial dos municípios pesquisados no Estado da Paraíba Fonte: Maracajá, 2013.

\section{RESULTADOS E DISCUSSÃO}

Os valores médios das pegadas hídricas das populações masculina e feminina, bem como o total geral de cada mesorregião do Estado da Paraíba são apresentados na Tabela 1. A pegada hídrica do Estado da Paraíba é de 761,7 $\mathrm{m}^{3} /$ ano, pouco superior a $\mathrm{PH}$ do lêmen, um dos paises mais pobre do mundo, que é de $619 \mathrm{~m}^{3}$ de água per capita por ano, enquanto os americanos consomem $2.482 \mathrm{~m}^{3}$ por pessoa no mesmo período (Hoekstra \& Chapagain, 2007).

Tabela 1. Valores médios das pegadas hídricas (PH) masculina, feminina e total das

\begin{tabular}{cccc} 
mesorregiões do Estado da Paraíba, expressos em mªno $^{3}$ an \\
Mesorregião/Estado & $\begin{array}{c}\mathrm{PH}- \\
\text { Masculina }\end{array}$ & $\begin{array}{c}\mathrm{PH}- \\
\text { Feminina }\end{array}$ & $\begin{array}{c}\mathrm{PH} \text { - } \\
\text { Total }\end{array}$ \\
\hline Mata paraibana & 876,6 & 801,1 & 838,8 \\
Agreste paraibano & 771,6 & 705,1 & 738,3 \\
Borborema & 755,3 & 690,2 & 722,7 \\
Sertão paraibano & 780,5 & 713,5 & 746,9 \\
Média & 796,0 & 727,5 & 761,7 \\
\hline
\end{tabular}

Fonte: Dados da pesquisa, 2013.

A mesorregião da Mata Paraibana tem a maior PH e a mesorregião da Borborema tem a menor $\mathrm{PH}$ do estado. Esse fato não está totalmente associado à disponibilidade hídrica da região, apesar de que no Litoral chover praticamente 3 vezes mais do que em algumas localidades da mesorregião da Borborema (Silva, 2004). Isso pode estar principalmente associado ao poder aquisitivo da população como demonstra a Figura 3, que exibe a relação entre a $\mathrm{PH}$ e o índice de desenvolvimento humano e a renda familiar. O coeficiente de 
determinação entre $\mathrm{PH}$ e renda familiar $\left(\mathrm{r}^{2}=0,8908\right)$ (Figura 3A) é bastante superior àquele entre $\mathrm{PH}$ e IDH $\left(\mathrm{r}^{2}=0,3359\right)$ (Figura $\left.3 \mathrm{~B}\right)$. Este resultado sugere que a $\mathrm{PH}$ da população é mais influenciada pelo nível de consumo de bens e serviços do que pelo IDH que expressa fatores como educação, expectativa de vida e produto interno bruto per capita.

Em geral a população com maior poder econômico consume mais, principalmente produtos com alta pegada hídrica. A pegada hídrica masculina é 8,6\% superior à pegada hídrica feminina em todas mesorregiões do Estado da Paraíba. Este resultado está associado ao fato que os homens consomem mais do que as mulheres, principalmente produtos alimentícios os quais têm alto conteúdo de água virtual embutido. Por outro lado, a PH do Estado da Paraíba representa 55,2\% da média brasileira e 61,2\% da média mundial que são de 1380 e $1243 \mathrm{~m}^{3}$ /ano per capita, respectivamente (Mekonnen \& Hoekstra, 2011).
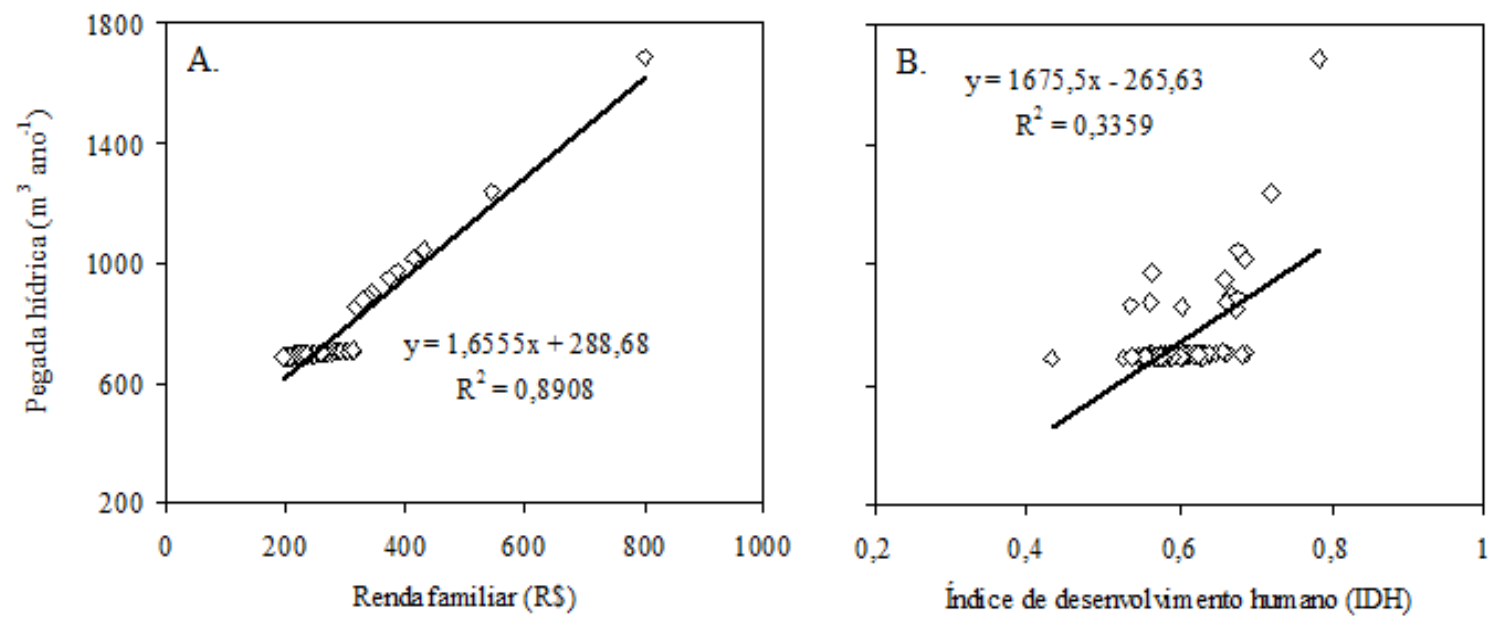

Gráfico 1. Relacionamento entre pegada hídrica e renda familiar (A) e pegada hídrica e índice de desenvolvimento humano - IDH (B) do Estado da Paraíba.

Fonte: Dados da pesquisa, 2013.

A PH do estado da Paraíba varia entre 688,7 a $1685,5 \mathrm{~m}^{3} /$ ano per capita (Figura 4). A média estadual de $796 \mathrm{~m}^{3}$ /ano per capita é apenas pouco superior à pegada hídrica média do Iêmen que é de $619 \mathrm{~m}^{3}$ ano per capita (Hoekstra et al., 2009), país árabe muito pobre que ocupa a extremidade sudoeste da Península da Arábia.

Os maiores valores da PH estão situados nas maiores cidades do estado, como João Pessoa, Campina Grande, Patos e Cajazeiras, em face do maior poder aquisitivo da população. Por outro lado, os menores valores de PH são encontrados nos entornos das cidades menos desenvolvidas, localizadas nas microrregiões do Cariri, Curimatau, Brejo Paraibano e algumas áreas do Sertão do estado. Na mesorregião da Mata paraibana a $\mathrm{PH}$ varia entre 691 e 1685,5 $\mathrm{m}^{3}$ /ano per capita, com média de $838,8 \mathrm{~m}^{3} /$ ano per capita; o Agreste paraibano entre 698,4 e $1240,4 \mathrm{~m}^{3}$ ano per capita, com média de $722,7 \mathrm{~m}^{3}$ ano per capita; 
Borborema entre 688,4 e $88,7 \mathrm{~m}^{3}$ ano per capita, com média $722,7 \mathrm{~m}^{3}$ ano per capita e Sertão paraibano entre 698,4 e 1047,7 $\mathrm{m}^{3}$ ano per capita, com média de $746,9 \mathrm{~m}^{3}$ ano per capita.

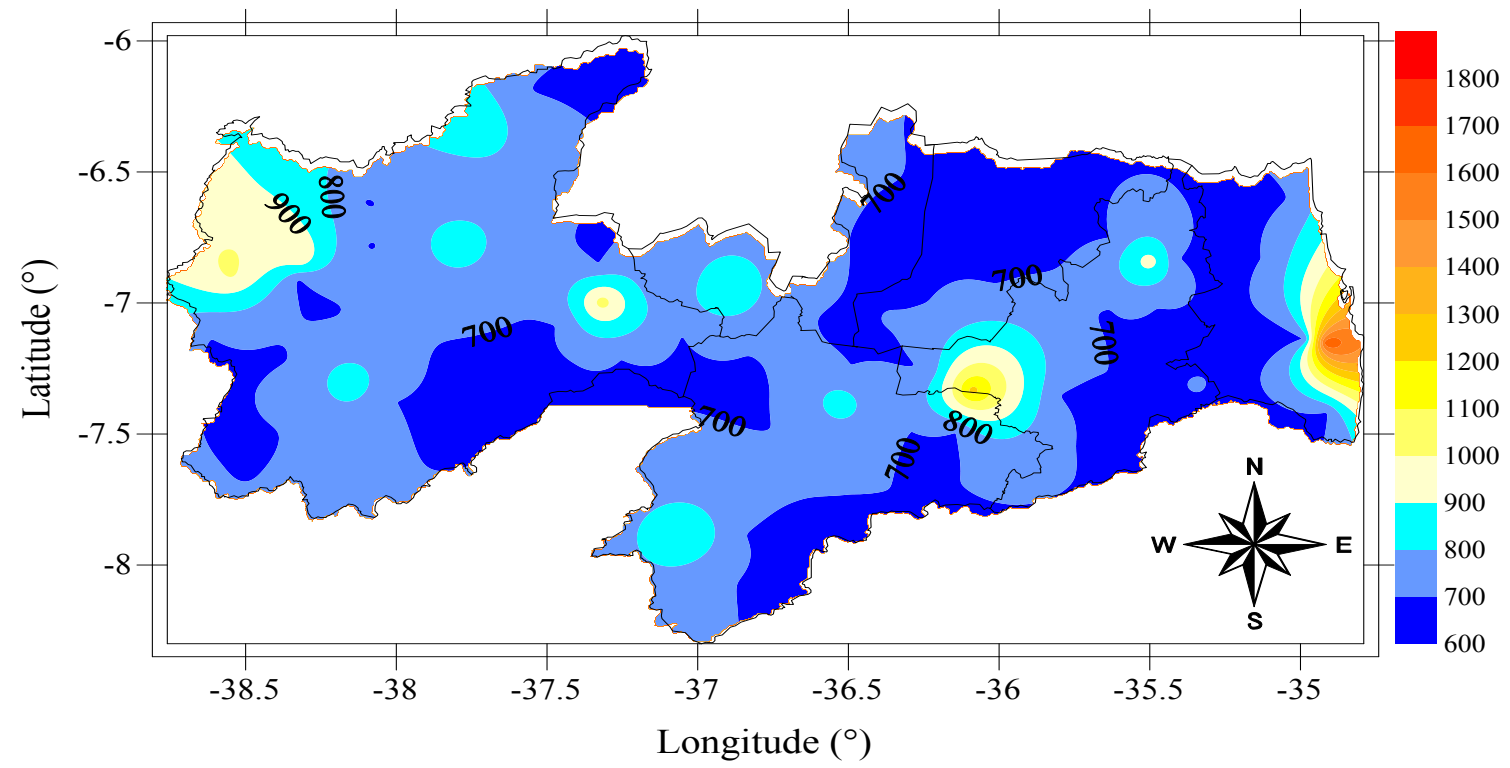

Figura 4. Distribuição espacial da pegada hídrica ( $\mathrm{m}^{3} /$ ano per capita) no Estado da Paraíba Fonte: Dados da pesquisa, 2013.

Os resultados aqui apresentados permitem inferir que a renda per capita exerce um impacto maior na $\mathrm{PH}$ em face de consumo maior de produtos de origem animal e industrial; a pegada hídrica do sexo masculino foi sempre superior a do sexo feminino em todas as classes e grupos de consumidores da região de estudo. É importante destacar que a população com uma renda per capita menor tem um alto consumo de cereais/grãos, diminuindo assim o consumo de carne vermelha por causa do seu preço elevado. Os consumidores vegetarianos foi o que apresentou a menor pegada hídrica. Esses resultados indicam que PH aumenta de acordo com a renda familiar e diminui em função dos hábitos alimentares. Dessa forma, a renda familiar anual também interfere na pegada hídrica, em face da água virtual acumulada nos bens e serviços, que é diretamente proporcional aos hábitos de consumo da população.

O relacionamento entre pegada hídrica e renda familiar e linear. Assim, quanto maior a renda familiar anual maior a pegada hídrica. Muito embora a renda familiar e a pegada hídrica da população do sexo masculino sejam maiores do que a do sexo feminino, essa diferença não é expressiva, em nenhum dos municípios analisados. Os resultados aqui apresentados indicam que a pegada hídrica da população pode ser minimizada através da mudança dos hábitos alimentares, bem como através da redução de consumo de produtos que envolvam a importação de água virtual; e, ainda, que grande parte da população desconhece os impactos dos hábitos alimentares sobre os recursos hídricos e ao meio ambiente. Nesse sentido, Chapagain \& Orr (2009) destacam 
que a PH se torna quase sustentável se o sistema em que a água for extraída for bem gerenciado, através da utilização conscientizada pelo consumidor.

A população não vegetariana com maior poder aquisitivo tem o consumo de água maior do que a população com renda familiar de até um salário mínimo. A renda familiar também interfere na pegada hídrica, em face da água virtual acumulada nos bens e serviços. Os consumidores não vegetarianos do sexo feminino têm $\mathrm{PH}$ menor do que o sexo masculino enquanto os consumidores vegetarianos do sexo feminino têm $\mathrm{PH}$ menor do que do sexo masculino. Portanto, a pegada hídrica pode ser uma informação de grande interesse dos planejadores, políticos e empresas de fornecimento de água que estão preocupados com o equilíbrio de oferta e demanda dos recursos hídricos dentro de suas respectivas áreas administrativas. Neste sentido, os estudos regionais sobre pegada hídrica nos diversos setores da atividade humana são relevantes no contexto atual, em que os recursos hídricos são bens preciosos e tornam cada vez mais escassos no milênio atual.

\section{CONSIDERAÇÕES FINAIS}

1. A metodologia da pegada hídrica é uma ferramenta adequada para se avaliar uso consuntivo de água de indivíduos, fornecendo subsídios que formam a base para a formulação de novas estratégias de gestão da água;

2. A pegada hídrica da população pode ser reduzida através da mudança dos hábitos alimentares, bem como através da redução de consumo de produtos que envolvam a importação de água virtual;

3. Os maiores valores da PH no Estado da Paraíba estão situados principalmente na mesorregião da Mata paraibana e em alguns pontos do Agreste Paraibano, assim como em diversas áreas do Sertão paraibano;

4. A pegada hídrica aumenta de acordo com a renda familiar e diminui em função dos hábitos alimentares.

\section{AGRADECIMENTOS}

A CAPES - Coordenação de Aperfeiçoamento de Pessoal de Nível Superior.

\section{REFERÊNCIAS}

ALDAYA, M. M.; SANTOS, P. M.; LLAMAS, M. R. Incorporating the water footprint and virtual water into policy reflections from the Mancha Occidental region, Spain. Water Resources Management, v. 24, p. 941-958, 2010. 
ANDRADE, B. B. Turismo e Sustentabilidade no Município de Florianópolis: Uma Aplicação do Método da Pegada Ecológica. Dissertação (Mestrado em Administração). Universidade Federal de Santa Catarina. Florianópolis, 2006, p.152.

BELLEN, H. M. Desenvolvimento sustentável: Uma Descrição das Principais Ferramentas de Avaliação. Ambiente \& Sociedade - Vol. VII n 1. jan./jul.2003.

Indicadores de Sustentabilidade: Uma Análise Comparativa. 2. ed. Rio de Janeiro: FGV, 2006.

CHAPAGAIN, A. K.; ORR, S. An improved water footprint methodology linking global consumption to local water resources: a case of Spanish tomatoes. Journal of Environmental Management, v. 90, p. 1219-1228, 2009.

DIAS, G. F. Pegada Ecológica e Sustentabilidade Humana. São Paulo: Gaia, 2002.

GUIMARÃES, R. P.; FEICHAS, S. A. Q. Desafios na Construção de Indicadores de Sustentabilidade. Revista Ambiente \& Sociedade, v. XXII, n.2, p. 307-323, jul-dez, 2009.

ERCIN, A. E.; ALDAYA, M. M., Hoekstra, A. Y. Corporate water footprint accounting and impact assessment: the case of the water footprint of sugarcontaining carbonated beverage. Water Resources Management, v. 25, p. 721741, 2011.

FENG, K.; SIU, Y. L.; GUAN, D.; HUBACEK, K. Assessing regional virtual water flows and water footprints in the Yellow River Basin, China: A consumption based approach. Applied Geography, v. 32, p.691-701, 2011.

GLEICK, P. H. The changing water paradigm: a look at twenty-first century water resources development. Water International, v. 25, p.127-138, 2000.

HOEKSTRA, A., Water Neutral: Reducing and Offsetting the Impacts of Water Footprints. UNESCO-IHE, Delft, 2008.

HOEKSTRA, A. Y.; CHAPAGAIN, A. K. Water footprints of nations: water use by people as a function of their consumption pattern. Water Resources Management, v. 21, p. 35-48, 2007.

HOEKSTRA, A.Y., CHAPAGAIN, A.K. Globalization of water: Sharing the planet's freshwater resources, Blackwell Publishing, Oxford, UK. In press, $2007 \mathrm{~b}$. 
HOEKSTRA, A. Y.; CHAPAGAIN, A. K. Globalization of water: sharing the Planet's freshwater resources. 1.ed. Oxford: Blackwell Publishing, 2008. 232p.

HOEKSTRA, A. Y.; HUNG, P. Q. Globalization of water resources: international virtual water flows in relation to crop trade. Global Environmental Change, v. 15, p. 45-56, 2005.

HOEKSTRA, A.Y., HUNG, P.Q. Virtual water trade: A quantification of virtual water flows between nations in relation to international crop trade, Value of Water Research Report Series, no 11, UNESCOIHE, Delft, 2002.

HOEKSTRA, A. Y. How sustainable is Europe's water footprint? Water and Wastewater International, v. 26, p. 24-26, 2011.

IBGE. Instituto Brasileiro de Geografia e Estatística. Indicadores de desenvolvimento sustentável: Diretoria de Geociências. Rio de Janeiro, 2002.

JACOBI, P. R. Educar na sociedade de risco: o desafio de construir alternativas. Pesquisa em Educação Ambiental, v.2, p. 49-65, 2007.

MARACAJÁ, K. F. B., CARVALHO, J. R. M. de, Ecological footprint method: anãlise da sustentabilidade ambiental no estado da Paraíba, 2007. Revista Querubim, ano 6, $\mathrm{n}^{\circ}$ 12, p. 27- 36, 2010.

MARACAJÁ, K. F. B. Nacionalização dos recursos hídricos: um estudo exploratório da Pegada Hídrica no Brasil. Tese de Doutorado. Programa de Pós-Graduação em Recursos Naturais. Universidade Federal de Campina Grande, 2013, p. 105.

MEKONNEN, M. M., HOEKSTRA, A. Y. The green, blue and grey water footprint of crops and derived crop products, Hydrology and Earth System Sciences, v. 15, p.1577-1600, 2011.

PEREIRA, L. G. Síntese dos Métodos de Pegada Ecológica e Análise Emergética para Diagnóstico da Sustentabilidade de Países: O Brasil como Estudo de Caso. Universidade Estadual de Campinas. Faculdade de Engenharia de Alimentos. Departamento de Engenharia de Alimentos, 2008.

PERRY, C. Efficient irrigation; inefficient communication; flawed recommendations. Irrigation and Drainage, v. 56, p. 367-378, 2007. 
RESENDE NETO, A. Sustentabilidade, água virtual e pegada hídrica: um estudo exploratório no setor bioenergético. Dissertação (Mestrado em Engenharia de Produção). Porto Alegre: Universidade do Rio Grande do Sul, Porta Alegre, 2011, p. 81.

ROMAGUERA, M.; HOEKSTRA, A. Y.; SU, Z.; KROL, M. S.; SALAMA, M. S. Potencial of using remote sensing techniques for global assessment of water footprint of crops. Journal Remote Sensing, v. 2, p. 1177-1196, 2010.

SILVA, V. P. R. On climate variability in Northeast of Brazil. Journal of Arid Environments, v.58, n.4, p.575 - 596, 2004.

VAN OEL, P. R.; MEKONNEN, M. M.; HOEKSTRA, A. Y. The external water footprint of the Netherlands: Geographically-explicit quantification and impact assessment. Ecological Economics, v. 69, p.82-92, 2009.

YU, Y.; HUBACEK, K.; FENG, K. GUAN, D. Assessing regional and global water footprints for the UK. Ecological Economics, v.69, p. 1140-1147, 2010.

ZHAO, X.; CHEN, B.; YANG, Z. F. National water footprint in an input-output framework-A case study of China 2002. Ecological Modeling, v. 220, p.245-253, 2009.

WACKERNAGEL, M., REES, W. Our ecological footprint. The new catalyst bioregional series. Gabriola Island, B. C.: New Society Publishers, 1996. 